\title{
Cultural Mixers: Race, Space, and INTERCULTURAL RELATIONS AMONG YOUTH IN EAST-END TORONTO
}

ANUPPIRIYA SRISKANDARAJAH

Abstract. The objective of this study is to examine the way youth negotiate belonging in two priority neighbourhoods - Malvern and Chester Li - in Toronto's east-end. It asks how youth experience belonging and negotiate difference in 'priority neighbourhoods'. In what ways does space shape belonging and difference? In contrast to previous studies that are spatially decontextualized, I argue that neighbourhoods are the very sites where youth negotiate differences and connections as they engage with peers, families, friends and residents. The importance of space in studying youth's sense of belonging is particularly valuable in Toronto where neighbourhoods are highly diverse and stratified. My work is inspired by Yuval-Davis's (2006) notion of belonging and the politics of belonging and Bourdieu's (1984) concepts of social field and habitus. I braid together a conceptual framework with the aim to achieve a more nuanced understanding of the ways power operates in the everyday context of 'priority neighbourhoods' and how processes of inclusion and exclusion and boundaries of belonging are demarcated.

Keywords: Habitus; Bourdieu; Toronto; Race; Neighbourhoods; Youth; Ethno-racial youth; Ethnography; Politics of belonging 


\section{INTRODUCTION}

This paper examines how the configuration of space and sense of inclusion and exclusion inform racialized youth's sense of belonging. Racialized youth are situated in a particular way within the Canadian context, shaped by inclusions and exclusions (Creese 2015; Cui 2012; Paragg 2015; Potvin 1999). Neighbourhoods are the very sites where everyday differences are both practiced and contested. However, the interactions between different ethno-racial ${ }^{1}$ groups in specific neighbourhoods are understudied. The focus of this paper is to interrogate how differences are constructed, interrogated, and policed between 'others' in spaces where there is significant diversity, and its implications for the experiences of belonging. Place is where influences and belongings intersect (Clayton 2004). Places (as material spaces) foster and even compel negotiation among those who share spaces (Massey 2005).

In this study I examine Malvern and Chester Le, two 'priority neighbourhoods"2 in Toronto's east-end. In what ways do neighbourhoods shape belonging and negotiations of difference? By belonging I refer to youth's identity, and the experiences of attachments that forge for them a sense of social inclusion in society. Identity is defined against another and therefore cannot be seen as a unified subjectivity, but rather as "always in a process of becoming" (Cupers 2005: 735). Through a process of "separation from and identification with", ideas are constructed of "who [people perceive] they are and what they should do" (Bendixsen 2013: 26). Identity is dependent on social interaction which is informed by broader structures. Identity formation is a "complex set of interlocking processes based in multiple social relations that is closely articulated with defining structures" (Proweller 1998: 6). Identity is shaped by local positionings (Ibid: 6).

I draw on the United Nations' (2017) formulation of youth as anyone from the ages of 15 to 24 . With increasing levels of youth unemployment, rising cost of living, longer time in school, adulthood is increasingly postponed. Therefore, I have chosen to include youth well into their 20s. Since youth have fewer resources than their adult counterparts, they often remain fixed in their local environments (Harris 2009). There-

1. I use the term ethno-racial to capture both ethnic and racial definitions of identities. The participants' identities were fluid; they drew on both identifiers. For example, a youth might self-identity as Jamaican and also identify as Black.

2. Neighbourhoods identified by the city as underserviced with high rates of poverty. As of 2014 'priority' label was replaced with 'NIA' (Neighbourhood Improvement Areas). However, 'priority neighbourhood' continues to be used in dominant and everyday discourses. 
fore, local places are important sites of young people's self-making (Harris and Wyn 2009).

Neighbourhood has "no single generalizable interpretation" (Kearns and Parkinson 2001). How neighbourhoods are officially defined might not correspond with how people living in the neighbourhood might define its borders (Barnes et al.2006). Therefore, it is important to recognize the scale of this space as being different depending on people's everyday existence (Eijk 2010). Based on Armbruster and Meinhof (2011), I center on neighbourhoods to study the everyday interrogation of differences; i.e., they do not have the same connotations of "homogeneity, uniformity, or sense of belonging" as other scales of belonging such as "imagined communities" associated with conceptualizations of nation-states (10).

\section{Ethno-Racial Youth in Canada}

This study seeks to re-scale belonging from attachment to the nation (Yuval-Davis 2006) to explore the role of neighbourhoods in the experiences of belonging. It explores whether individuals can simultaneously feel exclusion at the national level and attachment to sub-national spaces. Different conceptual approaches to research on ethno-racial youth in Canada demonstrate that they are differently positioned in ways that tend to undermine their inclusion, engender discrimination, or disadvantage them in particular social and economic spheres. Macro-level statistical studies of young people, for example, illustrate there is discrimination in the labour market (Krahn and Taylor 2005); uneven academic achievement (Thiessen 2009); and over-representation of racialized youth in the criminal justice system (Fitzgerald and Carrington 2011).

Questions of youth negotiating ethno-racial identities, difference, and belonging have been examined in the Canadian context. Existing literature illustrates how ethno-racial young people are differentially positioned and have distinctive experiences compared to their White counterparts, whether it is the over-surveillance of racialized youth in schools (Kayaalp 2014); youth as a time of racial identity making (Rajiva 2006); stereotyping and racialization of youth by police (Symons 1999); or second generation Muslim youth's decreased sense of belonging compared to other second generation youth (Wong and Simon 2009).

The Canadian ethno-racial youth literature also focuses on the racialization processes which illustrates the particularly marginalized experiences of Black youth. For example, Madibbo's (2008) study demonstrated that racism in the education and criminal justice system gravely informs 
the integration experiences of Black Francophone immigrant youth in Ontario. Black racialized youth are often negatively stereotyped in ways that limit their social opportunities. Carl James (2012: 464) found that stereotypes construct Black male youth as 'at-risk.' Branded as "immigrant, fatherless, troublemaker, athlete, and underachiever," Black youth are racialized in ways that negatively structures their life opportunities.

Despite this literature, there still exists a dearth in understanding the complex processes of 'living' difference and its implications for experiences of belonging as situated in particular spaces. I argue that in the Canadian literature the way difference and belonging are studied for the most part is spatially decontextualized (Moosa 2012; Netting 2006; Wong and Simon 2009). Space is either taken for granted or used as the backdrop for studies on difference and belonging without attending to its analytical significance or social qualities. Less is written on how sociospatial realities inform negotiations of difference and belonging.

\section{BeLONGING}

Yuval-Davis (2006) provides a sociological approach to understanding belonging as a process of attachment, identity, and recognition. She moves the concept of belonging beyond the purview of individual's psychological states and foregrounds the idea of belonging as a process constituted through boundary making--exclusion and inclusion. Moreover, Yuval-Davis (2006) offers analytic distinctions that are useful for unpacking the social and political threads that comprise belonging. I argue that these distinctions direct us to the locally embedded and interpersonal ways in which belonging may be experienced. Yuval-Davis examines both the individual and structural components of belonging.

According to Yuval-Davis (2006) belonging is constructed along three analytical levels: 1) social locations, 2) identifications and emotional attachments, and 3) ethical and political value systems. Social location refers to belonging to particular social groups. Belonging to social groups inform where individuals exist in the power relations and hierarchies of society, for example along axes of gender, race, and class. Secondly, Yuval-Davis (2006: 202) argues that belonging indicates identifications and "emotional investments and desire for attachments." Identities are narratives "people tell about who they are and who they are not" (pg. 203). These identities are constructed through "repetitive practices"; in particular, social contexts which create "identity narratives" (pg. 203). Therefore, identity narratives are not inherent; instead, they are an outcome of social practice. Finally, belonging also entails how 
social locations and identities are valued. This dimension of belonging is related to how boundaries of who and who does not belong are constructed and who draws these boundaries. Yuval-Davis (2006: 204) refers to the contestation of these boundaries and the ways social locations and identities are used as the "politics of belonging." In her approach the politics of belonging includes the boundary construction work of those in power but also how boundaries are forged and resisted by individuals. Therefore, belonging is essentially about exclusion and inclusion. Yuval-Davis's (2006) conceptualization of belonging illustrates that it is through everyday practices and contestations of belonging that the practical work of inclusion and exclusion occur.

While Yuval-Davis (2006) concentrates on nation and citizenship at the macro-level, I explore the boundaries of belonging constructed in daily encounters between individuals at the neighbourhood level. This is in line with Pettersson (2013: 420) who states the "intimate interplay between constructions of belonging and unbelonging" are an important element of belonging (italics added). Negotiations of belonging change depending on particular contexts (Pettersson 2013). Pettersson's insights enhance Yuval-Davis' (2006) approach by foregrounding everyday belonging in local neighbourhoods. I also argue that there is a spatial approach to belonging that complements Yuval-Davis' model.

\section{Neighbourhoods as Sites for the Politics of Belonging for Youth}

Space is important for studies on belonging (Youkhana 2015). Belonging as a concept centers relationships people have with others and their surroundings. Neighbourhood spaces shape and are themselves shaped by subjective interpretations. Subjectivity is co-constitutive with spatiality (Gulson 2011). It is in particular places that young people are both actors and acted upon. It is in "place where negotiation is forced upon us" (Massey 2005:154). Neighbourhoods are where differences are lived out and contested. Their spaces are imbued with power relations that shape subjectivity, practice, and sense of belonging. Space, including neighbourhood space, is socially produced, and thus, it should not to be regarded as 'natural' (Lefebvre 1991). Space and place are infused with socially constructed race, class, and gendered meanings.

Recently, Canadian ethno-racial youth scholarship recognizes space as an important marker of difference. Gosine and Islam's (2014) investigation of discrimination against youth in Toronto's Regent Park schools found a racial and class oppression enhanced their sense of community. Similarly, Zaami's (2015) work on Ghanaian youth in Toronto's Jane and 
Finch area found there was a dialectical relationship between social and spatial exclusion. The youth attributed their limited access to the labour market and increased racial profiling by police as an outcome of living in these spaces. Cairns's (2013: 624) study examined how rural White youth's identities in Southeastern Ontario are constituted through spatialized and racialized understandings. White youth struggling to escape labels such as "dirt," a term used to describe poor, rural youth, displaced this discourse onto racialized others living in urban spaces. This, in turn, allowed them to forge their self-worth.

Belonging comes into existence through material conditions as situated in space (Youkhana 2015). Writing about the Australian context, Harris (2016: 373) argues that youth's "narratives about difference depend on the space of belonging." Living in multicultural spaces requires constant negotiations of difference which can inform new shared identities or reiterate racial codings (Harris 2016). Youth are at the forefront of negotiating everyday difference due to their 'rootedness' in their communities. An "engagement with cultural difference" (Harris 2013: 584) is central to their participation in these local spaces.

\section{Belonging ANd Bourdieu}

My efforts to situate everyday difference and belonging in particular places and from a sociological perspective directed me to Pierre Bourdieu (1984). Bourdieu (1984) provides a sociological orientation which I employ to foreground the material and structural axes that inform youth negotiations of difference in their everyday lives.

Bourdieu (1984) conceptualizes social life as relational. These relations take two forms: fields-- objective positions of people that inform how they think and act-- and habitus - the way we "internally experience" the world (Wacquant 2013: 275). Bourdieu suggests that social practice and interaction occur in 'social fields.' Society is made up of these fields, and each has values and "regulative principles" (Bourdieu and Wacquant 1991: 17). Fields are actively shaped and continuously constructed. Field structures the habitus, which in turn constitutes the field as a world with value that is worth investment (Makoe 2006). I approach neighbourhood spaces as distinct social fields that inform the habitus of the participants inhabiting these places. Their social fields and habitus shape how they negotiate difference and experience belonging. Being from a particular neighbourhood or social field informs one's perspectives and actions. Bourdieu allows for thinking about everyday negotiations of belonging. 


\section{Methodology}

Ethnography is the examination of people in their natural environment whereby the aim is to understand their social meanings and everyday life. It requires the researcher to be immersed in the specific environment, a method referred to as participant observation (Brewer 2003). Researchers produce rich, detailed field notes which describes and makes sense of social settings and relationships to produce theoretically informed, contextualized accounts (O'Rielly 2005) or thick descriptions (Geertz 1973).

Ethnography is not restricted to a single paradigmatic orientation. The study and the questions I ask are informed by a critical realist perspective, whereby social inquiry is perceived as a reflexive ethical practice seeking to help those in unfair situations (Tracey 2012). The critical realist perspective (Lloyd 2000) focuses on how structural powers impose on social agents and how they use power to reinforce, subvert, or change structural impositions. Structures depend on "material resources" that have a "conditional" effect on agency (Kontos et al. 2011, pg. 120). However, it cannot determine agency. Agency is employed through "reflexive" dialogue wherein agents negotiate benefits and concerns that inform action (Kontos et al. 2011, pg. 120).

\section{Site: 'Priority Neighbourhoods'}

In the case of Toronto, as neighbourhoods have become more diverse over the last few decades they have also become more inequitable (Hulchanski 2010). Low-income areas where neighbourhood incomes have decreased are found mostly in the northeast and northwest parts of the city, home to most of the 'priority neighbourhoods'. 'Priority neighbourhoods' are characterized by high levels of poverty and limited access to social services (Strong Neighbourhood Task Force 2005). The diversification and income differentiation of neighbourhoods beg an examination of how diverse, marginalized local places cultivate the belonging of youth and how youth make sense of the differences that mark their neighbourhoods.

I conducted my research at a community center in Malvern and Chester Le, in the northeast part of the city. To conceal the identity of study participants, I have changed the names of the centers to Malvern Community Center and The Hub. I recognize this is not the only place youth in the neighbourhood socialize. Youth spend time at local malls, schools, parks, and at home. Unlike malls, parks, or their home, working in a community center setting allowed for exploring the relationship 
between youth, service providers, parents, and other neighbourhood residents including police and politicians who occasionally visited in a more confined setting. It allowed for fostering more meaningful relationships with the youth over a period of time. One major benefit of conducting observations at local community centers was that it enabled access to youth in a sphere where they felt comfortable and where power inequalities were somewhat more minimized than at home or at school. Unlike a school setting constricted by more entrenched institutional boundaries, community centers allowed access to youth in a more relaxed, less rigid environment. They choose to come and go as they desired. They participated in programs that interested them as opposed to being mandatory. In this environment, they had more power to choose if they wanted to participate. At the centers they were not subject to teacher or peer pressures to participate in the research or conform their narratives to prescribed expectations.

I carried out my ethnographic study for 16 months in the field from February 2013 to June 2014. I choose Malvern because that is the community in which I reside. Initially, I had chosen two neighbourhoods because I wanted to incorporate a more explicitly comparative analysis of both neighbourhoods. Chester Le was another 'priority neighbourhood' in the northeast part of the city. However, once in the field, I realized that despite the fact both spaces were 'priority neighbourhoods' they were indeed very different. Conducting a formal comparative analysis would have required reducing the complexities that shape these neighbourhoods into comparative criterions. It would have undermined the rich ways personal experiences, and neighbourhood realities were intertwined. Although at times it did allow for some comparisons between neighborhoods (which is out of the scope of this paper). I approached several community centers that serviced the neighbourhoods. I conducted my research at the two places where I was able to receive approval from the executive director.

Malvern is a large sprawling neighbourhood interspersed with a lot of greenery. For many it is hard to imagine it as a low-income 'priority neighbourhood' because parts of it look like an idyllic suburban neighbourhood. Malvern consists of a mixture of homes, public housing, privately owned homes, and rental apartments. Malvern has two high schools, one public and one Catholic. Top "visible minority" groups are South Asian, Caribbean Black, followed by Filipino and Chinese (City of Toronto 2016). Chester Le is composed mostly of townhouses owned by Toronto Community Housing Corporation. More than three-quarters of TCHC households make less than $\$ 20,000$ per year (Toronto Community Housing Corporation 2014). There are also a few privately-owned 
townhouses and detached homes and one apartment building. The community has an elementary school, but students have to leave the neighbourhood for high school. The population is a mix of Afro-Caribbean, Arab Muslim, Chinese, and Somali.

\section{Entering the field}

When I entered the field I introduced myself to the youth participants at the center as a Ph.D. student researcher. I briefly explained my purpose which was to examine youth belonging in their everyday lives in their neighbourhoods. Most of the participants were not particularly interested at the beginning of my fieldwork. However, after cultivating a stronger relationship I found the participants took a stronger interest in the research project.

I was involved in several youth programs at the centers. I spent five days a week in these settings, alternating between sites. Programs included general after-school drop-ins, tutoring, art workshops, boys' and girls' leadership groups, and girls' empowerment groups. I participated alongside the youth in program activities, including learning to write raps, performing my own spoken word pieces, preparing food for the breakfast programs, going on fieldtrips, discussing current events, and planning community events. After building rapport with youth in the programs, I offered them a choice to do an interview or participate in a focus group.

I begin with a brief overview of the participants. To ensure confidentiality of the participants I have not included detailed descriptions about their lives. Youth participants' ages varied from 16-24 years old. The young people for the most part had all been born in Canada, with a few who migrated at a young age. Some of the youth attended high school (almost all attended their local high school), college, or university, while others worked. Some youth lived in homes with both parents, singleparent, extended families, or divorced families. They dealt with a range of everyday issues, from parents' mental health, siblings with special needs, parents' illegal migration status and precarious work; and death of family or friends due to gang violence. I witnessed many of their amazing feats, including athletic, artistic, and academic achievements. I saw firsthand their resilience in spite of adversities and their continued optimism. Young people in the course of my research shared many details of their everyday life. They shared the various mundane, funny, and sometimes hard experiences of living with many "different cultures".

I conducted twenty-four semi-structured interviews with youth and seven focus groups (each consisting of 4-5 youth). The identifiers I have 
used are those self-identified by the youth. Youth included those who self-identified as Filipino, Latina, Ethiopian, Ghanaian, Tamil, Black, Jamaican, Caribbean, Arab Muslim, East Asian, Somalian, Yemeni, biracial (Black and White). Before exiting the field, I wanted to allow research participants to have a deeper understanding and involvement in the research project. Therefore, to redistribute power more equitably and engage youth in the research process, I incorporated photo-narratives. This was to allow youth to be able tell the story the way they wanted their stories to be told. Photo-voice also allowed me to transfer skills making the research process be more reciprocal. Photo-voice was used with the intentionality of it being an "empowerment technique" for disenfranchised youth (Gant et. al., 2009: 358). The findings of the photovoice exit project are out of the scope of this paper.

\section{Findings}

\section{"When Ethiopians Were in Ethiopia No One Said You Were Black": Negotiating Identity Making}

One of the most important themes that emerged in the study was the everyday negotiations of ethno-racial identity-making among the participants. Ethno-racial identities are important for the participants in the study and are a great source of pride. Marking out specificities of their identity is a way for youth to challenge the reduction of their differences. All participants acknowledged their strong ethno-racial attachments and its importance in their daily lives. For example, for Angela, her sense of belonging is rooted in her ethno-racial identity.

Angela: That is where my sense of, sense of belonging lies, that is where I feel the most community um, the most relatability, the most, um, like similar shared experiences. (Ethiopia, 24)

The findings in the study suggest ethno-racial identities are also racialized. Race permeated through and structured everyday minute interactions. As I try to capture here, race is interwoven with ethnic identities and the complex circumstances of young people who have diverse immigrant and ethnic family backgrounds. These identity constructions are fluid and constantly negotiated. An example of this is the complex negotiation of 'Blackness' by the youth participants. I found that Blackness is a localized identity mediated by migration to Canada, and informed by diasporic politics. For example, Angela, an Ethiopian youth, shared how she navigated both her own and her mother's views on Blackness. 
Many East African participants in the study discussed their parents' refusal to identify as Black and how they relayed this message to their children. Angela shared that her mother struggled with negotiating her transnational migration and was not able to identify with the prescribed racial category she experienced upon arrival in Canada. In Ethiopia, her mother was not considered 'Black.' Her mother's reluctance to associate herself with 'Blackness' and its negative connotations were reproduced in her child rearing and the expectations she placed on Angela's choices in friends. Angela was warned at an early age she should not make Jamaican friends because her mother viewed them as "trouble-makers" in the neighbourhood.

The distancing by Angela's mother from 'Blackness' was heightened in a neighbourhood context where Black was mostly associated with Jamaican. Unlike her mother, Angela identified as Black (and Ethiopian). Angela identified as Black partially because society prescribed this racial category. It was a racial category that she recognized does not exist in Ethiopia. In the process, she recognized it was an artificial, socially constructed category. The category was so pervasive that she could not escape it in its entirety, nor did she desire to completely resist it. She drew on the resources that accompanied the identity marker of Black for belonging. For example, whereby Ethiopian identity was not represented in media, Black identity was, whether in movies or popular music. Therefore, she was able to forge a sense of belonging and connection through her racialized identity. For Angela, due to the heavy association of 'Blackness' with Jamaican identity in her neighbourhood, there was less space to be 'Ethiopian'. In a racialized society such as Canada, cultural specificity is often erased and particular identity labels are constructed and made available.

Angela: A little information, when, when Ethiopians were in Ethiopia no one said you were Black, gang violence related to you, you are a thief. They all looked the same. And then they come here and all of a sudden, all they see is Jamaican this, Jamaican that, Black this, Black that, and so you know in their mind they associated Black with Jamaican. So being Tamil is being Indian. All Black people were Jamaican and then furthermore there is like. They are dangerous, you know, you don't want your kids to be influenced by them. Furthermore, they [parents] too were being identified as. It was something they were rejecting, oh I am not Black, I am not like that, I am Ethiopian, we don't do that. Um. So. There was that thing. So like my mom didn't want me to hang around with the Black kids... (Ethiopia, 24) 
Despite the many ways the participants navigated their identity construction, they all agreed that living with diverse groups of people allowed them a level of connection that made them comfortable and more accepting of difference. For some of the participants, living with diversity cultivated their ability to simultaneously traverse different groups. Tina spoke to her abilities to 'code-switch' when she was with her South Asian friends' parents versus her Caribbean friends' parents.

Tina: I just feel like I have been around too many different people. I am just subconsciously able to turn from how I should behave. I just feel like it is subconscious now. I don't even have to think about it anymore. (Latin America, 20)

Despite co-existence, however, for the most part participants in my study continued to interact most intimately with co-ethnics as illustrated in the second theme I discuss below: intercultural mixing.

\section{"Like Different Groups of People Look at Different Groups Differ- ently": Intercultural Mixing}

For the most part, the impression the participants gave was that different groups got along in their neighbourhoods. There were no major overt tensions or clashes that over-rode or dominated my interaction with them. However, there was less deep interaction between youth from different ethno-racial groups. This was reflected in the indifferent tone participants used when I asked whether people got along in their neighbourhood. For example, when I asked Jay, a 19-year-old Filipino youth "do people of different cultures get along in your neighbourhood?" he simply stated "yea I guess so."

\section{Inter-cultural relations and conflict}

The youth participants recognized that youth are particularly good at mixing with people of other ethno-racial groups. This was attributed to their shared experiences of migration. However, when challenges arose youth continued to construct boundaries around ethno-racial markers. Intragroup negative perceptions of others shaped youth's opinions of ethnic groups. Negative encounters with individuals would easily become a group issue. Youth culture often relies on peer groups to sanction friendships (Echols and Graham 2016; Miklikowska 2017).

Deque: Because at the end of the day it is like you see a group of people move and then you take that judgment by the collective you are in. (Ghana, 21) 
Tamil youth in Malvern discussed some of the derogative comments they received from Black youth, such as "Tamils' smell," "terrorists." Most Tamil participants stated that despite the fact that people tolerated others in their neighbourhood, there were some inter-ethnic tensions. For example, there were robberies taking place in the neighbourhood whereby Black youth targeted Tamil youth (and others, including other Black youth). For some of the Tamil participants, these robberies confirmed common racist tropes about Black youth as lazy, unwilling to find employment, and resorting to crime.

Pragash: Because in Malvern they [Black youth] are lazy to work. (Tamil 17)

Tamil participants did not question the structural reasons that lead some Black youths to rob or steal; for example, discrimination which often barred many Black youths from finding gainful employment. Nor did Tamil youth highlight violence or crime committed by fellow Tamil youth.

\section{Intercultural distancing: locating themselves in the racial hierarchy}

Intercultural relations were viewed in a positive light, but for the most part remained on a somewhat superficial level that did not necessarily mean friendships or inter-family ties. For some of the Tamil participants, there was a fear that inter-cultural mixing, more specifically friendships with Black youth, would have negative consequences. The fear came from stereotypical associations of Black youth with "crime", "drugs", and "failing school."

Tharan: It is always good to talk to different kind of people, it is always good to know other people. (Tamil 16)

Abalash: The bad is basically you might be chilling with the wrong crowd. (Tamil 17)

Arya: I went to drop my brother off at class, I think it was Malvern Mall. Yea it was Malvern Mall. So these uh Black kids they came up to me and my cousin was with me too. And they were like can I have 2 dollars. I said I don't have any money, and then they are like, is that why you have a Guess purse, and a cellphone, and everything. So I got scared, I just walked away. (Tamil 19) 
Simultaneously, some Tamil parents removed their children from 'Tamil' areas and schools in fear that their children would focus more on peer relations than academic achievement or get involved in gangs. Social distancing was not just between Black and Tamil youth. An East Asian youth disclosed her parents' rationale for moving to Markham (a suburb North of Toronto) was to distance her from "Brown" (Tamil) youth. It demonstrated the relative hierarchies between racialized groups.

Within the neighbourhood school space, a different power structure with its own hierarchies exist that affects peer relations and sense of belonging. Within the school context, Black youth ranked high in terms of "coolness." Black culture in particular, due to the popular appeal of African-American hip hop, allowed Black youth to carve out a unique space within the hierarchies of their local school.

Black Magic: At school I wouldn't say the youth because nobody wanted to be racist toward Black kids, if anything Black kids were most discriminating... (Jamaica, 21, male)

Deque: I think um, I did have other friends but I am saying like amongst, amongst those groups of people like that, that cool, quote on quote, we were mostly African or Caribbean um. Why I didn't have those friends, I guess, I guess, I guess there was a boundary type thing, where we were just not that open that time (Ghana, 21, male).

Deque was also perceived as "cool" because his brother had "street credibility' due to his involvement in street crime.

Deque: It wasn't as big as 'these guys are the Bloods, these guys are the Crips', it was more like it was like these guys are cool and they are, their older siblings had history type of thing.

Here "history" referred to being recognized in the neighbourhood for criminal activities or being 'tough'. These identities were deployed by the boys to perform a particular form of masculinity associated with their racial identities, one that emphasized 'toughness' and 'street smarts.' Street subcultures here emerge in part as a way to reclaim the local environment in response to youth who face unemployment and racism. In this setting, youth with limited opportunities for conventional social mobility created a street culture with its own ethno-racial hierarchies. For example, according to Rick and Donte, Chinese young people, for the most part, fear Jamaican youth in the neighbourhood. Only if they are really "comfortable", meaning that they possess their own form of street power would they be able to exert power. 
Rick: The Chinese, you have to be really comfortable to talk. (Jamaica, 19)

Donte: Yea. You have to be real comfortable to talk shit. (Jamaica,19)

In this context, "talk shit" meant to speak in a disrespectful manner.

\section{Policing identity boundaries}

I witnessed an incident in Malvern that was indicative of the ways race permeated everyday interactions and how these identities were policed by youth. One day, Jermaine, one of the Black youth, was excitedly telling some of the other boys during a program at the center that he wanted to join the "Asian"' break dance crew. Shaquille, another Black youth, however, was quick to tell Jermaine that he would not be as good as the break dancers in the group. Shaquille explained that since break dancing required mathematical abilities, Asians, who were more capable of making mathematical calculations, would be superior to Jermaine. Prasanth, a Tamil youth, agreed with Shaquille's argument. Jermaine seemed to mull over his peers' assertions and eventually agreed with their rationale. The example illustrated the minute ways youth policed each other's identities and what they deemed possible based on racial thinking in everyday interactions.

Another way identity boundaries are enacted is through intergenerational transmission (Dimitrova et al. 2015). Some parents started monitoring young people's friendships more as they entered high school.

Wendy: I think at this point their parents are like don't talk to other people, especially other cultures, stay with people I know, that I can recognize, that I can trust. And especially in high school [youth] tries to go against what they do. So I think parents feel more comfortable when people are like their own culture. (Tamil, 23)

Youth who did cut across these imaginary barriers and had inter-ethnoracial friendship groups were viewed as different. According to Tasha, even the hall monitors who were school staff thought she was strange for having friendships with different ethno-racial and interest-oriented groups.

Tasha: Like at school, even the hall monitors would look at me like I was crazy. They would be like honestly you are the only one in the school that can hang in any cliques and hang. I have hung out with the Tamils, Blacks, the sports people, even though I don't do sports, you will never find me in the gym, the nerds, everyone. (Middle Eastern, 18) 


\section{Intercultural economic comparisons}

Intercultural relations were informed by economic comparisons. By sharing their neighbourhoods with other ethno-racial groups, youth saw that some groups fared better, causing resentment.

Randy: Like the Chinese and Indian community they have huge support. I am not saying from the government, I am saying from corporations. It would be nice to see more cultures supported, we have a Chinese cultural center, Jewish centers, I don't really see Ghanaian centers... (Ghana, 21, male)

According to Randy, corporations gave more support to the Chinese and Indian community because they were perceived to have more economic capital which was beneficial to corporations.

These everyday comparisons structure youth's lives and what they deem possible. This is especially true in spaces where different groups are exposed to each other in their everyday lives. For example, Hadja (Somali, female, 24) was constantly reminded of this differentiation when she went to her local Tamil grocery store or walked by Tamil takeout stores and clothing shops found in her neighbourhood. She lamented that there were not many Somali stores. Similarly, Alias (Somali, female, 22) stated she did not know of a "rich" Somali person, but knew of many "rich" people in other ethno-racial communities in her neighbourhood.

Group relations varied in different spaces depending on local dynamics. It was in these spaces of inter-cultural mixing where it was possible to evaluate the relational aspects of difference. For example, Hadja evaluated Somalis in relation to Tamils because of the composition of her neighbourhood. The experiences of inter-ethnic relations in particular neighbourhood spaces lead to the next main theme that I discuss: difference as a spatialized lived reality.

\section{"When you Go to a White Area, I Feel Like I Don't Belong There": Space, Difference, and Belonging}

Participants had a racialized understanding of it meant to be Canadian. When asked what it meant to be Canadian Isabella simply stated:

Isabella: Honestly the first thing that comes to mind is White people. That is the first thing. (Tamil,23)

Participants stated that Whites were favoured for positions of power and employment. The continued criticism of Canada's promise of equality is a persistent theme in their narratives. 
Tina: Yea they do express multiculturalism but I mean I guess Canada needs to look at, although it was Natives that founded it first, I feel like a lot of White people are favoured... We are able to express ourselves, but when it comes to professional settings, we are probably not the first pick. (Latin American, 20)

Many of the participants recognized that despite Canada's claim as being a multicultural nation it is only major metropolitan centers like Toronto that are multicultural. Even within these cosmopolitan settings youth expressed experiences of discrimination. For example, for some of the youth, spatial mobility is heavily restricted, albeit self-imposed, primarily due to their ethnicity/race. Some youth discussed experiences of unease when they venture to non-diverse or "White areas."

Monroe: When you go to a White area, I feel like I don't belong there. (Jamaica, 16)

Monroe spoke of feeling othered and over-surveilled when going to areas she perceives as "White" spaces. Despite negative experiences in their neighbourhoods, many of the youth use their neighbourhoods as a resource to protect themselves from racism. Many participants prefer to stay in their neighbourhoods, citing they feel safe being with people of similar ethno-racial identities.

Angela: I think what it comes down to is like, like when that is all you have that is what you identify with. They [youth in the neighbourhood] can't even go out [outside their neighbourhood], well they can, but even for them to go out they can't...If you don't have nowhere else to connect with, you will make, you connect with where you at. Because you don't have anything else... (Ethiopian, 24)

Being in these neighbourhoods dispelled the fear of discrimination participants experience outside these neighbourhoods. The sense of unease is one of the reasons youth enjoy living in ethnic enclaves. In contrast, there is a deep sense of security living with others who are similar. The youth recognized racism had a spatial element, and realized that all citizens were not equal, especially those that lived in marginalized spaces of the city. They acknowledged that outside their neighbourhoods racialized people were not treated the same. For example, Tina discussed how shop owners in other areas treated racialized youth unfavourably compared to shop owners in Malvern. This only reconfirmed to the participants that they did not belong in certain places. 
Tina: I mean in an area like this I guess it is most apparent. I mean if you were a Caucasian they would probably say yes [to being accepted], but um just being able to seeing the way, the way people around here are treated by the police. Even store owners, not particularly in this area, but in other places than I would say a lot of people are not, they are not treated equal and people are helped by more of what they are look like then by what the law is... (Latin America, 20)

The experiences captured by the above excerpt illustrate that the racialized youth I interviewed often felt relegated to these spaces because they are met with disdain and suspicion when they leave the safety of their neighbourhoods. Though theoretically everyone is guaranteed freedom of mobility, these young people understood the discursive constructions that often limit their belonging and demarcate imagined spatial boundaries.

\section{Discussion}

Bourdieu's concepts of habitus can show how power is constructed and challenged in human interaction (Olsen 1995). Scholars have drawn on concepts of habitus to examine inter-cultural relations in multicultural settings. For example, Philippe Bourgois and Jeff Schonberg (2007: 7) used the concept of 'ethnicized habitus' to examine divisions among heroin users based on skin colour and how they were imposed through everyday interactions. For example, the way the drug was used (injection methods) and how drug users generated income differed along ethnic lines in relation to wider socio-economic realities. By looking at the "generative forces" of ethnicized habitus, it is possible to see how macro-power relations construct ways of being that "become inscribed on bodies and routinized in behaviours."

In this paper I showed how the configuration of spatial location, inclusion and exclusion, informed young people's sense of belonging. Youth's strong ties to their ethno-racial identity and their recognition of the marginalization of their spatial location and identities by dominant discourses oriented their disposition to one that viewed themselves as the 'other.' The lack of access to resources, racism, poverty, and exposure to crime all compounded to inform the way they saw the world, how they interacted with others, and subsequently how they negotiated belonging. Youth engaged in everyday negotiations required for living in diverse neighbourhoods. These negotiations informed their understanding of a more permeable idea of belonging founded in the unthreatening everydayness of diversity and through ethno-racial distancing. We saw how youth reproduced dominant discourses that informed their dispositions 
and values. For example, many felt that Canadianness is still associated with Whiteness. Whiteness is the norm against which everyone is assessed, even if it is accomplished subconsciously.

The participants also conveyed that their neighbourhoods created a unique way of being which made them comfortable to live and interact with different groups. Participants from each group had internalized many stereotypes about others. Despite this, they all had internalized the idea that getting along was good and a central component of Canadian identity. Thomas (2011), writing in the American context, found that youth drew on national discourses of multiculturalism that preached tolerance. However, at the local level, when asked what they thought about multiculturalism, her participants simply said everyone 'gets along' for the most part (Thomas 2011). A 'separate togetherness' often means solidarity across different groups is not found (Driskell et al. 2008). For Thomas (2011), the 'get along' discourse precluded looking at racism and hegemonic Whiteness. It was evident in the way youth reproduced negative discourses cemented in ideas perpetuated by White ideals. To only see resistance and deny internalized discourses overlooks concerns about the "workings of power" (Abu-Lughod 1990: 42).

For youth in these neighbourhoods ethno-racial identities are not simply essentialized characteristics, representational framings of their social locations, or strategic concepts they draw upon at will, but rather these identities are constitutive of their experiences. The paper showed that their ethno-racial identities are continuously negotiated and revealed they are a "process of becoming rather than being" (Hall 1996: 4). Youth's processes of identification and racialization are never finished or determined but always "“in process"” (Hall 1996: 2). Racialization, therefore, is reproduced at the everyday level, where the neighbourhood figured as an important, although often understudied aspect of everyday racialization.

Race also became part of the youth's interpretive repertoires which permeated their interaction. Race structured their lives and was spatially organized. Youth drew on race to navigate relationships with others. At times youth drew strategically on race to garner benefits. It was also a marker of difference that made them feel marginalized, viewed as the 'other', or created a sense of not belonging. Normative identities for youth were often marked along the lines of ethno-racial identities informing how they related to each other. For some, distancing was the only way to relate to their own normative identity. For example, for Asian youth in the study, it was cool to be 'nerdy.' This identity is distanced from the 'street tough' Black youth stereotype which reaffirmed both youth's position in the racial hierarchy and connection to their fellow ethno-racial peers. For the Tamil youth, focusing on academic 
success and cultural activities was one way they distanced themselves from Black youth. Some Tamil youth considered their Black youth counterparts as lazy and unwilling to adhere to values of hard work and economic success, which Tamil youth attributed to their own cultural upbringing. We also saw the multiple ways Black youth distanced themselves from other groups, whether it was by viewing them as less cool, nerdy, or physically weak. These stereotypes stemmed from interactions situated in particular spaces.

There are gaps in the literature on inter-cultural mixing as they happen in local neighbourhoods. The emerging literature that speaks to these realities predominantly addresses Black and Latino relations in America (Capetillo-Ponce 2010; Morales 2012). Inter-cultural research usually concerns Whites versus 'other' as if 'other' is a homogenous group (Valentine 2008). Less is known about the intergroup dynamics of youth. In a stratified racial system, youth are situated in various ways which inform their relations. To only focus on White-other relationships does not account for the intricate ways racialized systems work and locate different groups (Watkins et al. 2007). It is important to examine interethnic conflict and social distancing based on race/ethnicity because it has implications for generating more nuanced understandings of belonging. According to Capetillo-Ponce (2010), due to misconceptions about each other, racialized communities are often not able to build solidarity, which prevents their growth within White power structures. Inter-ethnic tensions need to be understood within wider structures determined by White hegemony, whereby others are often in conflict for scarce resources available to them (Capetillo-Ponce 2010). Colonial, stigmatized, and stereotypical views are transferred to groups when judging other groups.

I argued that in a racialized context, ethno-racial groups often engage in othering 'others' as they struggle to find their place within the wider racialized nation-building project. These ideologies heighten racism and promote social exclusion. However, there are moments of solidarity in these shared spaces that needs cultivation. It is in the everyday that social power is exercised and maintained, and simultaneously it is in these experiences where new forms of resistance can take place (Latham 2002). Inter-ethnic solidarity is important. However, according to de Finney (2010) policies that focus on superficial aspects of integration overlook the structural inequities that promote youth's social exclusion. They also affect relationships between groups and the potential for "multicultural engagement and civic solidarity" (de Finney 2010: 484).

In everyday interaction, structural racism or economic inequalities are understood as essentialized characteristics of groups (Bourgois and Schonberg 2007). For example, in my study I found that non-Black youth rarely interrogated the structural reasons that disproportionately 
affected Black youth's employment opportunities and education. Nor did non-Tamil youth question why it was problematic to call Tamil youth 'terrorists.'

These relations unfold within the context of a particular class as reflected by the neighbourhood in which the youth are situated. Young people's negotiations of difference and belonging are informed by the differential way in which they are economically situated within the city. They have varied ideas about the future, economic success, and each other. The character of the neighbourhood and the economic struggles embedded in these spaces play a constitutive role in how the participants see themselves.

\section{Conclusion}

The objective of this study was to examine the way youth experience belonging and negotiate difference in two 'priority neighbourhoods', Malvern and Chester Le. In what ways did local neighbourhood spaces inform belonging and negotiations of difference? Yuval-Davis (2006) provided a schema to understand the relationship between belonging and un-belonging; that belonging is framed by inclusions and exclusions. Structured by relations of power, individuals are located socially in ways that enable or disable their inclusion and the sense of connection that being a part of something affords. This approach tends to foreground the way national identities are produced to include some and exclude others through axes of race, gender, ethnicity, sexuality and class. Bourdieu (1984), however, offers valuable concepts, particularly that of social field and habitus to spatialize Yuval Davis's framework for belonging. In this way, I sought to rescale belonging onto the neighbourhood level. Habitus illuminates the way youth, in the case of this study, are positioned to reproduce the structures of power - institutions, norms and world views - in their everyday lives. I sought to elicit how youth made sense of these conditions, namely, how they interpreted their social world, particularly their understanding of difference, while also pointing to the way their sense of belonging is deeply structured by exclusions in which these neighbourhoods are embedded.

The limited focus on gender was both a practical and conceptual limitation. I sought to take an intersectional approach, but most of the programs at the community centers were male-dominated. Although there were programs specifically targeted at girls, the general programs were dominated by boys. Several youth service providers stated that this was because girls' mobility was more restricted. Their parents tended to be stricter about their after-school activities. Nevertheless, gender insights 
need to be pursued with more attention. A future area of research could explore how girls navigate difference in everyday life. What are the gendered and sexual particularities that young women face in their diverse neighbourhoods?

This paper highlighted the ambivalence that framed the experiences of youth in these spaces. They appreciated diversity, found it foundational for Canadian identity, but simultaneously 'othered' each other in their pursuit of belonging. The sense of ambiguity illustrates that young people live complex lives that are framed not simply by feelings of belonging or unbelonging. More accurately, sense of belonging is found along a spectrum that is informed by constant negotiations of multiple axes of difference as situated in particular spaces.

\section{REFERENCES}

Abu-Lughod, Lila. 1990. The romance of resistance: tracing transformations of power through Bedouin women. American Ethnologist 17 (1): 41-55.

Armbruster, Heidi and Meinhof, Ulrike Hanna. 2011. Introducing borders, networks, neighbourhoods: conceptual frames and social practices. In Negotiating Multicultural Europe: Borders, Networks, Neighbourhoods, edited by Heidi Armbuster and Ulrike Hanna Meinhof (Eds.), London: Palgrave Macmillan.

Hall, S. 1996. Introduction: who needs identity? In Questions of Cultural Identity, edited by Stuart Hall and Paul du Gay, Pp. 1-17. London: Sage Publications.

Baffoe, Michael. 2011. Navigating two worlds: new identity constructions as determinants for successful integration of new Black immigrant and refugee youth in Canadian society. Journal of Social Sciences 7 (4): 475-484.

Barnes, Jacqueline, Katz, Ilan, Korbin, E. Jill, and O'Brien, Margaret. 2006. Children and Families in Communities: Theory, Research, Policy and Practice. England: John Wiley and Sons, LTD.

Bendixen, Synnove. 2013. The Religious Identity of Young Muslim Women in Berlin: An Ethnographic Study. Boston: Brill.

Bourdieu, Pierre. 1984. Distinction: A Social Critique of the Judgment of Taste. Cambridge, Massachusetts: Harvard University Press.

Bourdieu, Pierre and Loic Wacquant. 1991. An Invitation to Reflexive Sociology. Chicago: University of Chicago Press.

Bourgois, P., and Schonberg, J. 2007. Intimate Apartheid: Ethnic Dimensions of Habitus among Homeless Heroin Injectors. Ethnography 8(1): 7-31.

Brewer, J. 2003. Ethnography. In The A-Z of Social Research, edited by Robert Lee Miller and John D. Brewer, 99-102 London: Sage Publications. 
Cairns, K. 2013. Youth, dirt, and the spatialization of subjectivity: an intersectional approach to White rural imaginaries. Canadian Journal of Sociology 38(4): 623-646.

Capetillo-Ponce, J. 2010. Black-Latino/a relations in Boston: two trends of collective identification. Latino Studies 8(2): 244-270.

City of Toronto. 2016. "Toronto Facts." Retrieved June 27, 2016 (http://www1. toronto.ca/wps/portal/contentonly?vgnextoid $=$ dbe $867 \mathrm{~b} 42 \mathrm{~d} 853410 \mathrm{VgnVC}$ $\underline{\text { M10000071d60f89RCRD\&vgnextchannel }=57 \mathrm{a} 12 \mathrm{cc} 817453410 \mathrm{VgnVCM}}$ $\underline{10000071 \mathrm{~d} 60 \mathrm{f} 89 \mathrm{RCRD})}$.

Clayton, John. 2004. The Everyday Politics of the Multicultural City. Ottawa: Economic and Social Research Council.

Creese, G. 2015. Growing up where 'no one looked like me': gender, race, hip hop and identity in Vancouver. Gender Issues 32(3): 201-219.

Cui, D. 2012. Two multicultural debates and the lived experiences of ChineseCanadian youth. Canadian Ethnic Studies 43/44(3-1): 123-143.

Cupers, K. 2005. Towards a nomadic geography: rethinking space and identity for the potentials of progressive politics in the contemporary city. International Journal of Urban and Regional Research, 29(4):729-739.

de Finney, Sandrina. 2010. 'We just don't know each other': racialized girls negotiate mediated multiculturalism in a less diverse Canadian city. Journal of Intercultural Studies 31 (5): 471-487.

Dimitrova, Radosveta, Ferrer-Wreder, Laura, Trost, Kari. 2015. Intergenerational transmission of ethnic identity and life satisfaction of Roma minority adolescents and their parents. Journal of Adolescence 45: 296.

Driskell, David, Fox, Carly, Kudva, Neema. 2008. Growing up in the New York: youth space, citizenship, and community change in a hyperglobal city." Environment and Planning A 40(12):2831-2844.

Echols, L., \& Graham, S. 2016. For better or worse: Friendship choices and peer victimization among ethnically diverse youth in the first year of middle school. Journal of Youth and Adolescence 45(9): 1862-1876.

Eijk, Gwen Van. 2010. Does living in a poor neighbourhood result in network poverty? A study on local networks, locality-based relationships and neighbourhood settings. Journal of Housing and the Built Environment: 467-480.

Fitzgerald, R.T and Carrington, P. J. 2011. Disproportionate minority contact with the police in Canada. Canadian Journal of Criminology and Criminal Justice 53(4): 449-486.

Gant, L. M., Shimshock, K., Allen-Meares, P., Smith, L., Miller, P., Hollingsworth, L. A., and Shanks, T. 2009. Effects of photovoice: civic engagement among older youth in urban communities. Journal of Community Practice 17(4): 358-376.

Geertz, C. 1973. The Interpretation of Cultures. New York: Basic Books. 
Gosine, K., and Islam, F. 2014. 'It's like we're one big family': marginalized young people, community, and the implications for urban schooling. School Community Journal 24(2): 33-62.

Gulson, Kalervo N. 2011. Education Policy, Space and the City: Markets and the (In) visibility of Race. New York: Routledge.

Hall, S. 1996. Introduction: who needs identity? In Questions of Cultural Identity, edited by Stuart Hall and Paul du Gay, Pp. 1-17. London: Sage Publications.

Harris, Anita. 2009. Shifting the boundaries of cultural spaces: young people and everyday multiculturalism." Social Identities 15 (2): 187-205.

Harris, Anita. 2013. Young People and Everyday Multiculturalism. New York: Routledge.

Harris, A. 2016. Belonging and the uses of difference: young people in Australian urban multiculture. Social Identities 22(4): 359-375.

Harris, A., and Wyn, J. 2009. "Young people's politics and the micro-territories of the local. Australian Journal of Political Science 44(2), 327-344.

Hulchanski, J David. 2010. The Three Cities Within in Toronto: Income Polarization among Toronto's Neighbourhoods, 1970-2005. Toronto: Cities Press.

James, C. E. 2012. Students "at risk": stereotypes and the schooling of Black boys. Urban Education 47(2): 464-494.

Kayaalp, D. 2014. Educational inclusion/exclusion of Turkish immigrant youth in Vancouver, Canada: a critical analysis. International Journal of Inclusive Education 18(7): 655-668.

Kearns, Ade and Parkinson, Michael. 2001. The Significance of Neighbourhood. Urban Studies 38(12): 2103-2110.

Kontos, P. C., Miller, K., Mitchell, G. J., and Cott, C. A. 2011. Dementia care at the intersection of regulation and reflexivity: a critical realist perspective. Journals of Gerontology Series B: Psychological Sciences and Social Sciences 66B (1): 119-128.

Krahn, H., and Taylor, A. 2005. Resilient teenagers: explaining the high educational aspirations of visible-minority youth in Canada. Journal of International Migration and Integration 6(3-4): 405-434.

Latham, Alan. 2002. Research, performance, and doing human geography: some reflections on the diary-photograph, diary interview method. Environment and Planning A 35: 1993-2017.

Lefebvre, Henri. 1991. The Production of Space (Translated Donald NicholsonSmith). Oxford: Blackwell.

Lloyd, C. 2000. Globalization: beyond the ultra-modernist narrative to a critical realist perspective on geopolitics in the cyber age. International Journal of Urban and Regional Research 24(2): 258-273. 
Olsen, Kevin. 1995. Habitus and body language: towards a critical theory of symbolic power. Philosophy and Social Criticism 21(2): 23-49.

Madibbo, A. 2008. The integration of Black Francophone immigrant youth in Ontario: challenges and possibilities. Canadian Issues: 45-49.

Makoe, M. Q. 2006. South African distance students' accounts of learning in socio-cultural context: a habitus analysis. Race, Ethnicity and Education 9(4): $361-380$.

Massey, Doreen. 2005. For Space. London: Sage Publications.

Miklikowska, M. 2017. Development of anti-immigrant attitudes in adolescence: The role of parents, peers, intergroup friendships, and empathy. British Journal of Psychology 108(3): 626-648.

Moosa, Al-Rahim. 2012. Cultural reflections of Afghan youth living in Canada. Forced Migration Review 40:27.

Morales, E. 2012. Parental messages concerning Latino/Black interracial dating: an exploratory study among Latina/o Young adults. Latino Studies 10(3): 314-333.

Netting, N. S. 2006. Two-lives, one partner: Indo-Canadian youth between love and arranged marriages. Journal of Comparative Family Studies 37(1): 129-146.

Paragg, J. 2015. "Canadian-First": mixed race self-identification and Canadian belonging. Canadian Ethnic Studies 47(2): 21-44.

Pettersson, T. 2013. Belonging and unbelonging in encounters between young males and police officers: the use of masculinity and ethnicity/race. Critical Criminology 21(4): 417-430.

Potvin, M. 1999. Second-generation Haitian youth in Quebec: between the "real" community and the "represented" community. Canadian Ethnic Studies 31(1): 43-72.

Proweller, A. 1998. Constructing female identities: meaning making in an upper middle class youth culture. Albany: State University of New York Press.

O’Reilly, Karen. 2005. Ethnographic Methods. New York: Routledge.

Rajiva, M. 2005. Bridging the generation gap: exploring the differences between immigrant parents and their Canadian-born children. Canadian Issues, 2528.

Rajiva, M. 2006. Brown girls, White worlds: adolescence and the making of racialized selves. The Canadian Review of Sociology and Anthropology 43(2): 165-183.

Strong Neighbourhoods Task Force. 2005. Strong Neighbourhoods: A Call to Action. Retrieved 27 September 2016. http://74.1 25.95. 132/ search?q=cache:CWJOdTD3zmsJ:www.toronto.ca/ demographics/sntf.ht $\underline{\mathrm{m}+\text { Toronto+United }+ \text { Way }+\% 22 \text { Strong }+ \text { Ndghbourhoods }+ \text { Task }+ \text { Force } \% 22}$ $\underline{\& c d=}=4 \&^{\wedge}=$ en $\& \mathrm{ct}=\mathrm{clnk} \& \mathrm{gl}=\mathrm{ca}$. 
Symons, G. L. 1999. Racialization of the street gang issue in Montreal: a police perspective. Canadian Ethnic Studies 31(1): 124-138.

Thiessen, V. 2009. The pursuit of postsecondary education: a comparison of First Nations, African, Asian, and European Canadian youth. Canadian Review of Sociology 46(1): 5-37.

Thomas, Mary, E. 2011. Multicultural Girlhood: Racism, Sexuality, and the Conflicted Spaces of American Education. Pennsylvania: Temple University Press.

Toronto Community Housing Corporation. 2014. Toronto Community Housing Corporation Annual Report 2014. Retrieved June 25, 2016 (https://www. torontohousing.ca/about/publications/Documents/TCH_AR14_Final. pdf).

Tracy, Sarah J. 2012. Qualitative Research Methods - Collecting Evidence, Crafting Analysis, Communicating Impact. West Sussex: Wiley-Blackwell.

United Nations. 2017. What do we mean by “youth". Retrieved Wednesday May 1, 2019 (http://www.unesco.org/new/en/social-and-human-sciences/themes/ youth/youth-definition/).

Valentine, G. 2008. Living with difference: reflections on geographies of encounter. Progress in Human Geography 32(3): 323-337.

Wacquant, L. 2013. Symbolic power and group-making: on Pierre Bourdieu's reframing of class. Journal of Classical Sociology 13(2): 274-291.

Watkins, N. D., Larson, R. W., and Sullivan, P. J. 2007. Bridging intergroup difference in a community youth program. American Behavioral Scientist 51(3): 380-402.

Wong, L. L., \& Simon, R. R.2009. Citizenship and belonging to Canada: religious and generational differentiation. Canadian Issues: 3-14.

Youkhana, E. 2015. A conceptual shift in studies of belonging and the politics of belonging. Social Inclusion 3(4): 10-24.

Yuval-Davis, Nira 2006. Belonging and the politics of belonging. Patterns of Prejudice 40 (3): 197-214.

Zaami, M. 2015. 'I fit the description': experiences of social and spatial exclusion among Ghanaian immigrant youth in the Jane and Finch neighbourhood of Toronto. Canadian Ethnic Studies 47(3): 69-89.

Anuppiriya Sriskandarajah is an assistant professor in the Children, Childhood and Youth Program at York University. She is a sociologist by training and teaches research methodology. Her research interests include youth belonging, racialization and space.

Email: sriskana@yorku.ca 